\title{
Increasing Returns to Scale
}

\author{
Altiplano 8 (JP rock) Dr Jean Paul Faguet \\ Reader in the Politir
Programme Director, Development Management
}

This post is a response to Professor Teddy Brett's October Blog post entitled 'International
Inequality and the Global Crisis - Managing Markets for Sustainable Growth'

I find the question of scale economies particularly interesting because it seems incredibly dry and technical, but takes us into an economic and philosophical la-la land of implications that are incredible. If increasing returns are significant, persistent, and cross sectoral, then we should expect the entire world economy to eventually be dominated by one firm with a huge number of divisions. This firm will be more efficient than anyone else at producing everything. All prices should approach zero, because as scale increases the marginal cost of producing everything will fall relentlessly. It scales really are increasing, then you cannot have multiple producers and competing products in the same product space, because there will always be one in any category which is cheaper, made by the dominant firm. Then the mechanics and predictions of competitive markets in your classical economics breakdown.

This is not only problematic for theory. It also simply doesn't look like the world we inhabit. This is a much more serious problem. We observe different markets with different numbers of producers, and many markets where competitive firms are constantly emerging and manage to survive. The assumption of decreasing returns to scale maybe analytically convenient, and it is, but it also predicts a world that looks closer to the one we actually see.

In between increasing and decreasing returns to scale is the fragile world of constant returns to scale. This one is tricky because the theoretical demands are so high. In a Cobb-Douglas production function, alpha and beta must sum to exactly 1 for this world to exist. Not $0.999999 \ldots$ as that would be decreasing returns to scale, and not $1.0000 \ldots 01$, as that would be increasing returns to scale, however mild both. There are enough stochastic shocks in any economy as to make this unlikely.

In the end, the problem is not about assuming anyone of these naively, but rather about specifying a range of production in which returns are increasing, after which they become constant and then decreasing, as this is the kind of assumption that is most likely to be realistic by far. And to make such an assumption we must justify it. This is the interesting bit. I've now strayed well beyond any area of expertise, but my guess is that you could collapse a lot of the core of classical, neoclassical, and Marxist economics into different sets of assumptions about when returns are increasing, constant, or decreasing.

There have been 2 previous responses to Teddy Brett's original post by Guenther Schoenleitner, Director, International Financial Institutions Division, Federal Ministry of Finance, Austria. Read Part 1 and Part 2. 
